\title{
Synergistic effect $p$-phenylenediamine and $n, n$ diphenylthiourea on the electrochemical corrosion behaviour of mild steel in dilute acid media
}

\author{
Roland Tolulope Loto ${ }^{1} \cdot$ Abimbola Patricia Popoola $^{2} \cdot$ Akanji Lukman Olaitan $^{2}$
}

Received: 6 June 2015/ Accepted: 7 October 2015/Published online: 17 November 2015

(C) The Author(s) 2015. This article is published with open access at Springerlink.com

\begin{abstract}
Electrochemical studies of the synergistic effect of $p$-phenylenediamine and $n, n$ diphenylthiourea (TPD) as corrosion inhibitor of mild steel in dilute sulphuric and hydrochloric acid through weight loss and potentiodynamic polarization at ambient temperature were performed. Experimental results showed the excellent performance of TPD with an optimal inhibition efficiency of 88.18 and $93.88 \%$ in sulphuric and 87.42 and $87.15 \%$ in hydrochloric acid from both tests at all concentration studied. Polarization studies show the compound to be a mixed-type inhibitor. Adsorption of deanol on the steel surface was observed to obey the Langmuir and Frumkin isotherm models. X-ray diffractometry confirmed the absence of corrosion products and complexes. Optical microscopy confirmed the selective inhibition property of TPD to be through chemical adsorption on the steel surface.
\end{abstract}

Keywords Corrosion - Inhibitor · Adsorption · Organic · Acid

\section{Introduction}

Carbon steel is extensively utilized in petrochemical plants, chemical processing plants, extractive industries, and construction and automobile industries due to its good

Roland Tolulope Loto

tolu.loto@gmail.com

1 Department of Mechanical Engineering, Covenant University, Ota, Ogun, Nigeria

2 Department of Chemical, Metallurgical and Materials Engineering, Tshwane University of Technology, Pretoria, South Africa mechanical, chemical and physical properties [1-6]. These steels are exposed to the deteriorating effect of acids in a variety of different ways resulting in corrosion. Hydrochloric acid is the most difficult of the common acids to handle from the pointview of corrosion and materials of constructions. Extreme care is required in the selection of materials to handle the acid by itself, even in relatively dilute concentrations, or in process solutions containing appreciable amounts. This acid is very corrosive to mild steel. In industries, hydrochloric acid solutions are often used in order to remove scale and salts from steel surfaces, cleaning tanks and pipelines, production of organic and inorganic compounds, regeneration of ion exchange resins, oil production, etc. Hydrochloric acid is widely used for various treatments of materials in industry. The aqueous electrolyte phase in the overhead condenser, which comes from the brine water in the crude and steam stripping, contains mostly hydrochloric acid which is released by hydrolysis of calcium chloride $\left(\mathrm{CaCl}_{2}\right)$ and magnesium chloride $\left(\mathrm{MgCl}_{2}\right)$ and also contains hydrogen sulphide $\left(\mathrm{H}_{2} \mathrm{~S}\right)$ The corrosion in this unit is mostly due to the condensed $\mathrm{HCl}$. Sulphuric acid is produced more than any other chemical in the world. It has large scale uses covering nearly all industries, such as fertilizer industries, petroleum refinery, paint industry, steel pickling, extraction of non-metals and manufacture of explosives. In chemical industries, it is used for the production of dye stuffs, pharmaceuticals and fluorine. Sulphuric acid is widely used in industries such as pickling, cleaning and descaling, industrial cleaning agent and production of chemicals. Corrosion is an electrochemical process through results in the gradual deterioration of ferrous alloys through redox reactions [7]. This anomaly demands the perpetual search for more effective and versatile corrosion inhibiting compounds, due to the differential environmental conditions encountered in industry. This remains a centrepiece in corrosion prevention 
as inhibitors decelerate the electrochemical processes responsible for corrosion. The application of inhibitors is one of the most cost effective methods for corrosion control in acidic media [8]. Most common inhibitors employed in industry are compounds of organic origin whose basic constituents are nitrogen, oxygen and sulphur atoms. Inhibitors consisting of double or triple bonds facilitate the adsorption of the organic compounds onto metal surfaces, forming an impenetrable protective barrier through chemisorption reactions [9-17]. The chemical bond is formed between the electron pair and/or the pi-electron of the protonated species and the valence metal ions at the surface, thereby reducing corrosive attack in an acidic medium. Most compounds of synthetic origin are toxic, environmentally unfriendly and of high cost; thus, there is a need for low-cost, highly effective compounds [18]. Thiourea derivatives and $p$-phenylenediamine have been studied individually in previous research for corrosion inhibition properties with mixed results [1923]; however, this research aims to study the synergistic effect of $n, n$ diphenylthiourea and $p$-phenylenediamine as corrosion inhibitor for low carbon steel in $1 \mathrm{M}$ sulphuric and $0.5 \mathrm{M}$ hydrochloric acid.

\section{Experimental procedure}

\section{Material specimen}

Low carbon steel obtained commercially and analysed at the Advanced Materials and Tribo-Corrosion Research Laboratory, Department of Chemical and Metallurgical Engineering, Tshwane University of Technology, South Africa, gave a percentage weight composition of $0.401 \% \mathrm{C}, 0.169 \% \mathrm{Si}$, $0.440 \% \mathrm{Mn}, 0.005 \% \mathrm{P}, 0.012 \% \mathrm{~S}, 0.080 \% \mathrm{Cu}, 0.008 \%$ $\mathrm{Ni}, 0.025 \% \mathrm{Al}$, with the rest composed of Fe. The specimen dimension is cylindrical with $14 \mathrm{~mm}$ diameter.

\section{Inhibiting compound}

Combined mixture of $n, n$ diphenylthiourea and $p$ phenylenediamine in equal proportions resulting in a whitish, solid powder (TPD) is the inhibitor used. $n, n$ Diphenylthiourea was obtained from Sigma-Aldrich, St. Louis, USA, and $p$-phenylenediamine was obtained from Merck Chemical, Germany. The structural formula of $n, n$ diphenylthiourea is shown in Fig. 1a, the molecular formula is $\mathrm{C}_{13} \mathrm{H}_{12} \mathrm{~N}_{2} \mathrm{~S}$, while the molar mass is $228.312 \mathrm{~g} / \mathrm{mol}$. The molecular formula $p$ phenylenediamine is $\mathrm{C}_{6} \mathrm{H}_{4}\left(\mathrm{NH}_{2}\right)_{2}$, while the molar mass is $108.1 \mathrm{~g} / \mathrm{mol}$. The chemical structure is shown in Fig. 1b. TPD was prepared in molar concentrations of $0.0037,0.0074$, $0.0112,0.0149,0.0186$ and 0.0223 , respectively.

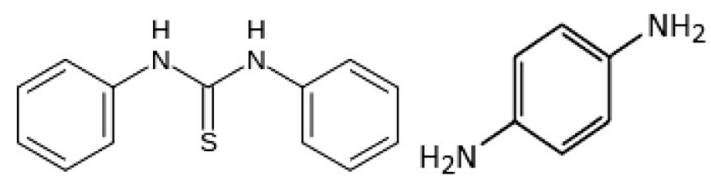

(a)

(b)

Fig. 1 a Chemical structure of $n, n$ diphenylthiourea, b chemical structure of 1,4-diaminobenzene

\section{Test solution}

$1 \mathrm{M} \mathrm{HCl}$ acid and $0.5 \mathrm{M} \mathrm{H}_{2} \mathrm{SO}_{4}$, both with $2 \%$ recrystallized $\mathrm{NaCl}$ of Analar grade, were used as the corrosion test solution.

\section{Preparation of low carbon steels}

The low carbon steel (14 mm diameter) was machined into predetermined dimensions with an average length of $10 \mathrm{~mm}$. The exposed ends of each steel were metallographically prepared with silicon carbide abrasive papers of $80,120,220,800$ and 1000 grits, washed with distilled water, rinsed with acetone, dried and stored in a dessicator for coupon analysis and potentiodynamic polarization.

\section{Weight-loss experiments}

Carbon steel samples were each immersed in $200 \mathrm{ml}$ of the acid solutions $\left(1 \mathrm{M} \mathrm{HCl}\right.$ and $\left.0.5 \mathrm{M} \mathrm{H}_{2} \mathrm{SO}_{4}\right)$ at predetermined molar concentrations of the organic mixture (TPD for $240 \mathrm{~h}$ at $25{ }^{\circ} \mathrm{C}$ ambient temperature). Each sample was taken out every $48 \mathrm{~h}$, washed with distilled water, rinsed with acetone, dried and re-weighed. Graphical plots of inhibition efficiency $(\eta)$ versus exposure time (h) (Figs. 2, 3 ) for the test media were made from the obtained data (Table 1).

The corrosion rate $(C)$ is determined from the equation below:

$R=\left[\frac{87.6 M}{D A T}\right]$

$M$ is the weight loss (mg), $D$ is the density $\left(\mathrm{g} / \mathrm{cm}^{2}\right), A$ is the surface area in $\mathrm{cm}^{2}$, and $T$ is the exposure time (h). The $\eta$ was calculated from the equation below.

$\eta=\left[\frac{C_{1}-C_{2}}{C_{1}}\right] \times 100$

where $C_{1}$ and $C_{2}$ are the corrosion rates with and without of predetermined concentration of TPD. The surface coverage is calculated from the equation below: 
Fig. 2 Plot of corrosion rate versus exposure time for 0-0.0037 M TPD in $0.5 \mathrm{M}$ $\mathrm{H}_{2} \mathrm{SO}_{4}$

Fig. 3 Plot of inhibition efficiency versus exposure time for $0-0.0037 \mathrm{M}$ TPD in $0.5 \mathrm{M}$ $\mathrm{H}_{2} \mathrm{SO}_{4}$
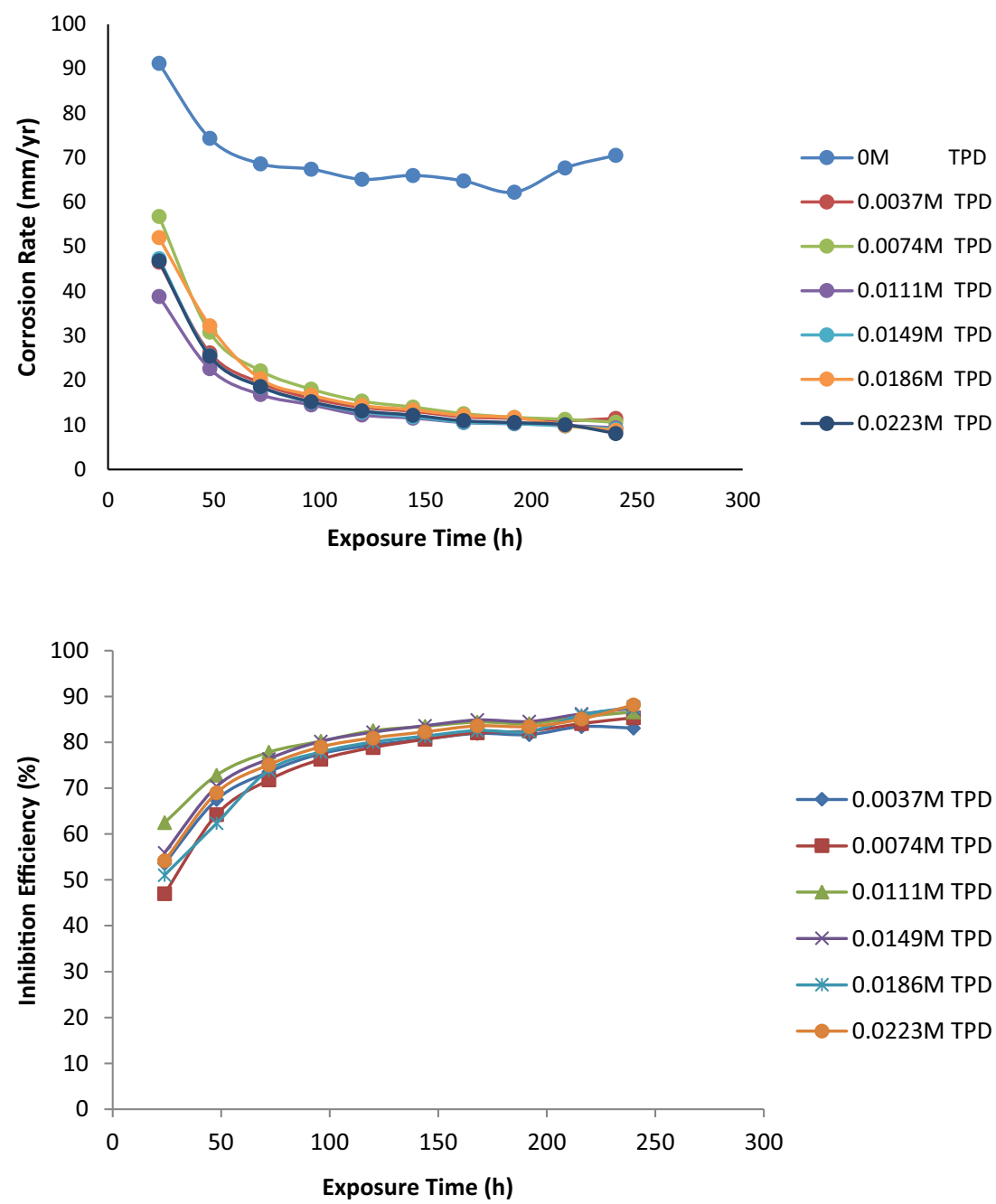

Table 1 Data obtained from weight loss analysis for low carbon steel in $0.5 \mathrm{M} \mathrm{H}_{2} \mathrm{SO}_{4}$ in $(0.0037-0.0223 \mathrm{M}) \mathrm{TPD}$ at $240 \mathrm{~h}$

\begin{tabular}{lllllll}
\hline Samples & $\begin{array}{l}\text { Weight } \\
\text { loss }(\mathrm{g})\end{array}$ & $\begin{array}{l}\text { Corrosion rate } \\
(\mathrm{mm} / \mathrm{year})\end{array}$ & $\begin{array}{l}\text { Inhibition efficiency } \\
(\%)\end{array}$ & $\begin{array}{l}\text { TPD concentration } \\
(\%)\end{array}$ & $\begin{array}{l}\text { Surface coverage } \\
(\theta)\end{array}$ & $\begin{array}{l}\text { TPD concentration } \\
(\mathrm{mol} / \mathrm{L})\end{array}$ \\
\hline A & 2.498 & 70.556 & 0 & 0 & 0 & 0 \\
B & 0.422 & 11.459 & 83.12 & 0.0025 & 0.8312 & 0.0037 \\
C & 0.366 & 10.584 & 85.35 & 0.005 & 0.8535 & 0.0074 \\
D & 0.334 & 9.342 & 86.62 & 0.0075 & 0.8662 & 0.0111 \\
E & 0.314 & 9.090 & 87.41 & 0.01 & 0.8741 & 0.0149 \\
F & 0.308 & 8.797 & 87.69 & 0.0125 & 0.8769 & 0.0186 \\
G & 0.295 & 8.096 & 88.18 & 0.015 & 0.8818 & 0.0223 \\
\hline
\end{tabular}

$\theta=\left[1-\frac{M_{2}}{M_{1}}\right]$

where $\theta$ is the quantity of TPD adsorbed per gram (or $\mathrm{kg}$ ) of the steel surface. $M_{1}$ and $M_{2}$ are the weight loss of carbon steel specimen in the free and inhibited test media.

\section{Potentiodynamic polarization}

Potentiodynamic polarization tests were performed with the aid of cylindrical steel samples embedded in resin mounts with exposed surface of $154 \mathrm{~mm}^{2}$. The working electrodes were polished with differential grades of silicon carbide paper, rinsed with distilled water and dried with 
acetone. Polarization tests were performed at ambient temperature of $25{ }^{\circ} \mathrm{C}$ with Digi-Ivy potentiostat. A platinum rod was used as the counter electrode and silver chloride electrode $(\mathrm{Ag} / \mathrm{AgCl})$ with $\mathrm{pH}$ of 6.5 was used as the reference electrode. The potentials were scanned from -1.5 to $+1.5 \mathrm{~V}$ at a scan rate of $0.002 \mathrm{~V} / \mathrm{s}$. The corrosion current $\left(i_{\text {corr }}\right)$, corrosion current density $\left(I_{\text {corr }}\right)$ and corrosion potential $\left(E_{\text {corr }}\right)$ were determined from the Tafel plots of potential versus $\log I_{\text {corr }}$. The corrosion rate $(R)$, the degree of surface coverage $(\theta)$ and the percentage inhibition efficiency (\% IE) were calculated from the equation below:

$R=\frac{0.00327 \times I_{\text {corr }} \times \mathrm{Eq}}{D}$

where $I_{\text {corr }}$ is the current density $\left(\mu \mathrm{A} / \mathrm{cm}^{2}\right), D$ is the density $\left(\mathrm{g} / \mathrm{cm}^{3}\right), \mathrm{Eq}$ is the specimen equivalent weight $(\mathrm{g})$.

The percentage inhibition efficiency $(\eta)$ was calculated from the corrosion rate with the equation below:

$\eta=1-\left[\frac{C_{2}}{C_{1}}\right] \times 100$

$C_{1}$ and $C_{2}$ are the corrosion rates in the absence and presence of TPD, respectively.

\section{Optical microscopy characterization}

The surface morphology of the inhibited and non-inhibited steel samples was further studied after weight-loss analysis with the aid of Nikon Eclipse LV 150 optical microscope for which micrographs were taken.

\section{X-Ray diffraction analysis}

X-ray diffraction (XRD) patterns of the film formed on the metal surface with and without TPD addition were analysed using a PANalytical X'Pert Pro powder diffractometer in $\theta-\theta$ configuration with an $\mathrm{X}^{\prime}$ Celerator detector and variable divergence and fixed receiving slits with Fe-filtered $\mathrm{Co}-\mathrm{K} \alpha$ radiation $(\lambda=1.789 \AA)$. The phases were identified using X'Pert Highscore plus software.

\section{Results and discussion}

\section{Weight-loss measurements}

Weight loss of low carbon steel during the exposure hours, with and without TPD additions in $0.5 \mathrm{M} \mathrm{H}_{2} \mathrm{SO}_{4}$ and $1 \mathrm{M}$ $\mathrm{HCl}$ acid at $25^{\circ} \mathrm{C}$, was evaluated. The calculated values of weight loss $(M)$, corrosion rate $(C)$, surface coverage $(\theta)$ and the percentage inhibition efficiency $(\eta)$ are presented in Tables 1, 2. Figures 2 and 3 show the graphical plot of corrosion rate and $\eta$ versus exposure time at predetermined concentrations of TPD in $\mathrm{H}_{2} \mathrm{SO}_{4}$, while Figs. 4 and 5 show the variation of corrosion rate and $\eta$ with exposure time in $1 \mathrm{M} \mathrm{HCl}$. In Fig. 2, the corrosion rate values of samples in $0 \mathrm{M}$ TPD acid solution were significantly high throughout the experimental evaluation period with slight decrease until 68-h exposure time where the corrosion rate was generally constant. This slightly contrasts the corrosion rate values in Fig. 4 for samples in $0 \mathrm{M}$ TPD $\mathrm{HCl}$ solution where the corrosion rates though very high throughout the exposure period declined progressively. The high corrosion rates in both solutions are due to the corrosive nature of the reactive species in the acid media which rapidly destroys the steel interfacial properties and substrate metal.

Addition of specific concentrations of TPD $(0.0037-0.0223 \mathrm{M})$ in both acids $(1 \mathrm{M} \mathrm{HCl}$ and $0.5 \mathrm{M}$ $\mathrm{H}_{2} \mathrm{SO}_{4}$ ) significantly decreased the corrosion rates; however, the corrosion rate values are much lower in $0.5 \mathrm{M}$ $\mathrm{H}_{2} \mathrm{SO}_{4}$ than $1 \mathrm{M} \mathrm{HCl}$. The $\eta$ values are proportional to the corrosion rates. In $0.5 \mathrm{M} \mathrm{H}_{2} \mathrm{SO}_{4}$, the $\eta$ increased from generally low percentage to very high values with time; the high values are associated with effective inhibition and protection of the steel, indicating the time-dependent effective inhibition performance of TPD in $0.5 \mathrm{M} \mathrm{H}_{2} \mathrm{SO}_{4}$. In $1 \mathrm{M} \mathrm{HCl}$ solution, the inhibition efficiency was generally high from the onset showing the time-independent characteristics of TPD inhibition performance in $1 \mathrm{M} \mathrm{HCl}$. At 240-h exposure time, the corrosion data in Tables 1 and 2 show an inhibiting compound that effectively inhibits corrosion of the steel sample through adsorption onto the

Table 2 Data obtained from weight loss analysis for low carbon steel in $1 \mathrm{M} \mathrm{HCl}$ in $(0.0037-0.0223 \mathrm{M}) \mathrm{TPD}$ at $240 \mathrm{~h}$

\begin{tabular}{|c|c|c|c|c|c|c|}
\hline Samples & $\begin{array}{l}\text { Weight loss } \\
(\mathrm{g})\end{array}$ & $\begin{array}{l}\text { Corrosion rate } \\
\text { (mm/year) }\end{array}$ & $\begin{array}{l}\text { Inhibition efficiency } \\
(\%)\end{array}$ & $\begin{array}{l}\text { TPD concentration } \\
(\%)\end{array}$ & $\begin{array}{l}\text { Surface coverage } \\
(\theta)\end{array}$ & $\begin{array}{l}\text { TPD concentration } \\
(\mathrm{mol} / \mathrm{L})\end{array}$ \\
\hline A & 3.488 & 126.60 & 0 & 0 & 0 & 0 \\
\hline B & 0.559 & 15.97 & 83.97 & 0.0025 & 0.8397 & 0.0037 \\
\hline $\mathrm{C}$ & 0.317 & 8.32 & 90.92 & 0.005 & 0.9092 & 0.0074 \\
\hline $\mathrm{D}$ & 0.341 & 8.83 & 90.23 & 0.0075 & 0.9023 & 0.0111 \\
\hline $\mathrm{E}$ & 0.471 & 12.38 & 86.50 & 0.01 & 0.8650 & 0.0149 \\
\hline $\mathrm{F}$ & 0.363 & 11.74 & 89.59 & 0.0125 & 0.8959 & 0.0186 \\
\hline G & 0.439 & 12.10 & 87.42 & 0.015 & 0.8742 & 0.0223 \\
\hline
\end{tabular}


Fig. 4 Plot of corrosion rate versus exposure time for $0-0.0037 \mathrm{M}$ TPD in $0.5 \mathrm{M} \mathrm{HCl}$
Fig. 5 Plot of inhibition efficiency versus exposure time for $0-0.0037 \mathrm{M}$ TPD in $0.5 \mathrm{M}$ $\mathrm{H}_{2} \mathrm{SO}_{4}$
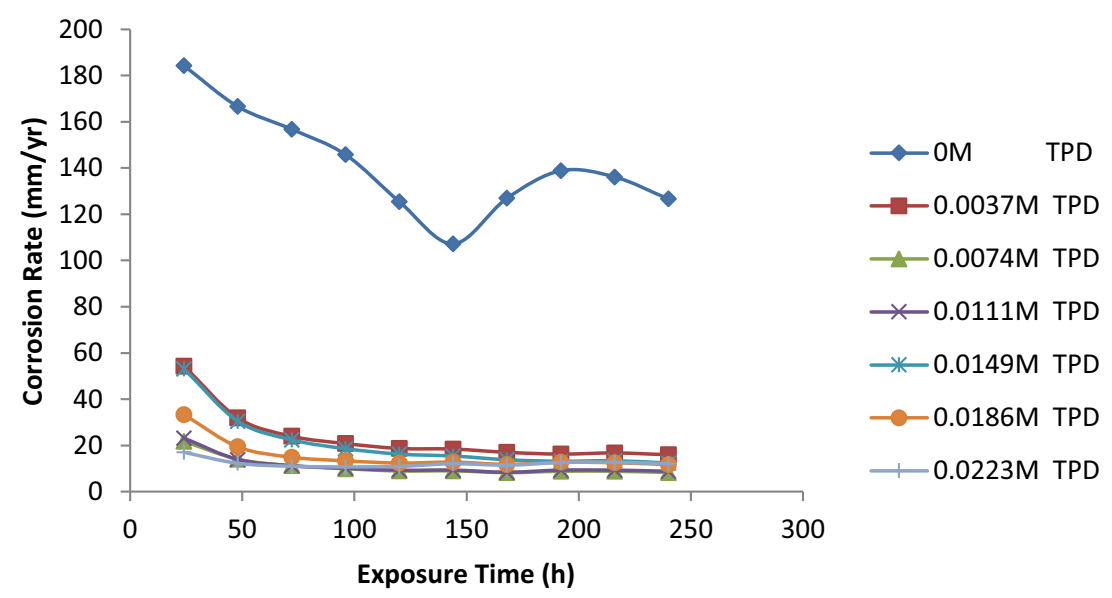

Exposure Time (h)

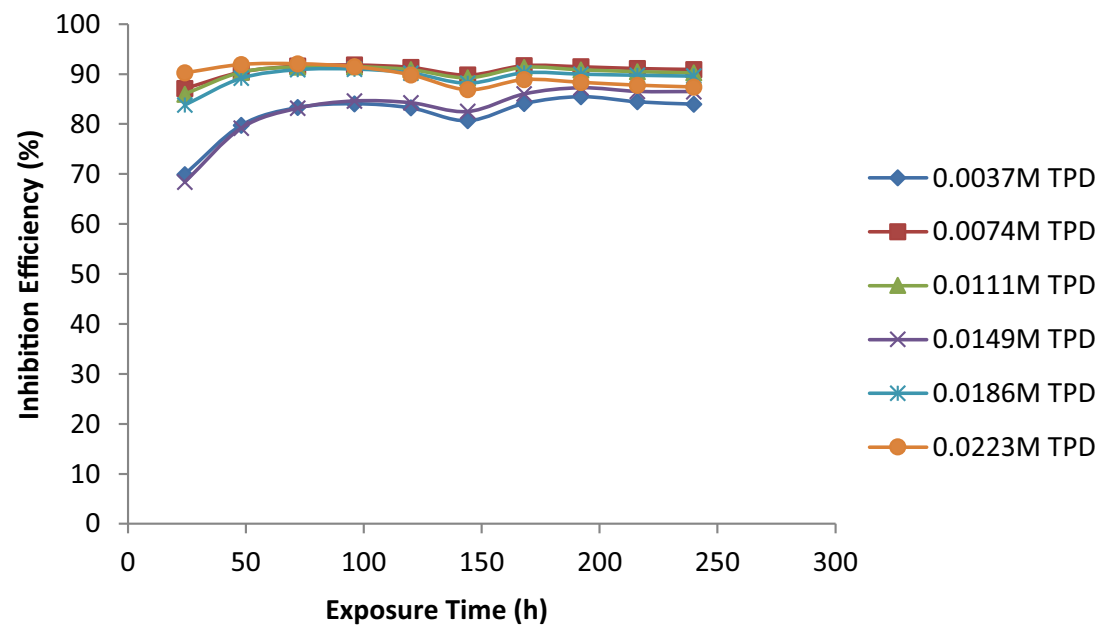

steel surface forming a protective covering through chemical reactions with the ionized steel surface [24]. TPD inhibits the redox reaction processes responsible for corrosion due to donor acceptor interactions between the pielectrons of the heteroatoms and the vacant $d$ orbital of steel surface atoms [25]. The electrochemical reactions are stifled over the active sites of the metal/solution interface due to the electrolytic action of TPD molecules.

\section{Potentiodynamic polarization}

The polarization data for the electrochemical influence of TPD on the corrosion behaviour of low carbon steel in $0.5 \mathrm{M} \mathrm{H}_{2} \mathrm{SO}_{4}$ and $1 \mathrm{M} \mathrm{HCl}$ are shown in Tables 3 and 4, while the polarization plots are shown in Figs. 6 and 7. Observation of Table 3 shows the progressive decrease in corrosion rate with increase in TPD concentration. At the highest concentration of $0.0223 \mathrm{M} \mathrm{TPD}$, the corrosion rate is the lowest with the value of $0.344 \mathrm{~mm} /$ year and inhibitor efficiency is the highest at $93.88 \%$. This shows that the performance of TPD is subject to the inhibitor concentration as observed from the previous discussion on weight loss. The corrosion potential varied differentially, tending towards cathodic and anodic inhibition potentials from $-0.380 \mathrm{~V}(0 \mathrm{M}$ TPD $)$. This depicts the influence of TPD on inhibiting the anodic dissolution process and hydrogen evolution reactions. The influence of TPD on the steel corrosion rates in $1 \mathrm{M} \mathrm{HCl}$ is significantly smaller than in $0.5 \mathrm{M} \mathrm{H}_{2} \mathrm{SO}_{4}$ as shown in Table 4. Comparison of the corrosion rates shows the remarkable difference in values between Tables 3,4 . The corrosion rates are generally higher in $1 \mathrm{M} \mathrm{HCl} \mathrm{com-}$ pared to $0.5 \mathrm{M} \mathrm{H}_{2} \mathrm{SO}_{4}$, though the rates significantly reduce in the presence of TPD in $1 \mathrm{M} \mathrm{HCl}$, and it increased minimally with increase in TPD concentration before reducing slightly after $0.0149 \mathrm{M}$ TPD. The corrosion potentials in $1 \mathrm{M} \mathrm{HCl}$ displayed similar electrochemical behaviour with the values in $0.5 \mathrm{M} \mathrm{H}_{2} \mathrm{SO}_{4}$. The polarization behaviours in both acid solutions are generally the same.

Study of previous research on $p$-phenylenediamine in $\mathrm{HCl}$ and $\mathrm{H}_{2} \mathrm{SO}_{4}$ shows that desorption occurs at very low 
Table 3 Potentiodynamic polarization data for low carbon steel in $0.5 \mathrm{M} \mathrm{H}_{2} \mathrm{SO}_{4}$ at $0.0037-0.0223 \mathrm{M} \mathrm{TPD}$

\begin{tabular}{lllllllrr}
\hline $\begin{array}{l}\text { TPD } \\
\text { concentration } \\
(\mathrm{mol} / \mathrm{L})\end{array}$ & $\begin{array}{l}\text { Corrosion } \\
\text { rate } \\
(\mathrm{mm} / \mathrm{year})\end{array}$ & $\begin{array}{l}\text { Corrosion } \\
\text { potential }(\mathrm{V})\end{array}$ & $\begin{array}{l}\text { Cathodic } \\
\text { slope } \\
(\mathrm{A} / \mathrm{V})\end{array}$ & $\begin{array}{l}\text { Anodic } \\
\text { slope } \\
(\mathrm{A} / \mathrm{V})\end{array}$ & $\begin{array}{l}\text { Polarization } \\
\text { resistance }(\Omega)\end{array}$ & $\begin{array}{l}\text { Corrosion } \\
\text { current }(\mathrm{A})\end{array}$ & $\begin{array}{l}\text { Corrosion current } \\
\text { density }\left(\mathrm{A} / \mathrm{cm}^{2}\right)\end{array}$ & $\begin{array}{l}\text { Inhibition } \\
\text { efficiency } \\
(\%)\end{array}$ \\
\hline $0 \mathrm{M}$ & 5.631 & -0.380 & -7.055 & 7.44 & 34.42 & $7.47 \mathrm{E}-04$ & $4.85 \mathrm{E}-04$ \\
$0.0037 \mathrm{M}$ & 0.959 & -0.392 & -7.821 & 14.20 & 201.99 & $1.27 \mathrm{E}-04$ & $8.26 \mathrm{E}-05$ & 82.93 \\
$0.0074 \mathrm{M}$ & 0.594 & -0.385 & -7.815 & 13.46 & 326.05 & $7.88 \mathrm{E}-05$ & $5.12 \mathrm{E}-05$ & 89.42 \\
$0.0111 \mathrm{M}$ & 0.645 & -0.346 & -6.521 & 16.80 & 300.50 & $8.55 \mathrm{E}-05$ & $5.55 \mathrm{E}-05$ & 88.53 \\
$0.0149 \mathrm{M}$ & 0.479 & -0.379 & -7.902 & 15.12 & 404.61 & $6.35 \mathrm{E}-05$ & $4.12 \mathrm{E}-05$ & 91.48 \\
$0.0186 \mathrm{M}$ & 0.532 & -0.374 & -7.005 & 13.01 & 364.44 & $7.05 \mathrm{E}-05$ & $4.58 \mathrm{E}-05$ & 90.54 \\
$0.0223 \mathrm{M}$ & 0.344 & -0.317 & -8.697 & 9.73 & 563.44 & $4.56 \mathrm{E}-05$ & $2.96 \mathrm{E}-05$ \\
\hline
\end{tabular}

Table 4 Potentiodynamic polarization data for low carbon steel in $0.5 \mathrm{M} \mathrm{HCl}$ at $0.0037-0.0223 \mathrm{M}$ TPD

\begin{tabular}{|c|c|c|c|c|c|c|c|c|}
\hline $\begin{array}{l}\text { TPD } \\
\text { concentration } \\
(\mathrm{mol} / \mathrm{L})\end{array}$ & $\begin{array}{l}\text { Corrosion } \\
\text { rate } \\
(\mathrm{mm} / \text { year })\end{array}$ & $\begin{array}{l}\text { Corrosion } \\
\text { potential (V) }\end{array}$ & $\begin{array}{l}\text { Cathodic } \\
\text { slope } \\
(\mathrm{A} / \mathrm{V})\end{array}$ & $\begin{array}{l}\text { Anodic } \\
\text { slope } \\
\text { (A/V) }\end{array}$ & $\begin{array}{l}\text { Polarization } \\
\text { resistance }(\Omega)\end{array}$ & $\begin{array}{l}\text { Corrosion } \\
\text { current (A) }\end{array}$ & $\begin{array}{l}\text { Corrosion current } \\
\text { density }\left(\mathrm{A} / \mathrm{cm}^{2}\right)\end{array}$ & $\begin{array}{l}\text { Inhibition } \\
\text { efficiency } \\
(\%)\end{array}$ \\
\hline $0 \mathrm{M}$ & 5.646 & -0.386 & -7.243 & 2.966 & 34.26 & $7.50 \mathrm{E}-04$ & $4.87 \mathrm{E}-04$ & 0 \\
\hline $0.0037 \mathrm{M}$ & 2.201 & -0.381 & -7.842 & 13.140 & 250.99 & $1.02 \mathrm{E}-04$ & $6.65 \mathrm{E}-05$ & 84.86 \\
\hline $0.0074 \mathrm{M}$ & 2.501 & -0.387 & -8.512 & 11.120 & 355.98 & $7.22 \mathrm{E}-05$ & $4.69 \mathrm{E}-05$ & 89.33 \\
\hline $0.0111 \mathrm{M}$ & 2.525 & -0.387 & -8.100 & 12.530 & 243.85 & $1.05 \mathrm{E}-04$ & $6.84 \mathrm{E}-05$ & 84.42 \\
\hline $0.0149 \mathrm{M}$ & 3.102 & -0.381 & -7.963 & 9.987 & 313.05 & $8.21 \mathrm{E}-05$ & $5.33 \mathrm{E}-05$ & 87.86 \\
\hline $0.0186 \mathrm{M}$ & 2.256 & -0.370 & -7.580 & 10.110 & 214.72 & $1.20 \mathrm{E}-04$ & $7.77 \mathrm{E}-05$ & 82.30 \\
\hline $0.0223 \mathrm{M}$ & 2.687 & -0.385 & -7.719 & 12.450 & 295.76 & $8.69 \mathrm{E}-05$ & $5.64 \mathrm{E}-05$ & 87.15 \\
\hline
\end{tabular}

Fig. 6 Comparison plot of polarization scans for low carbon steel in $0.5 \mathrm{M} \mathrm{H}_{2} \mathrm{SO}_{4}$ solution at $0 \mathrm{M}$ TPD

$-0.0223 \mathrm{M}$ TPD concentration

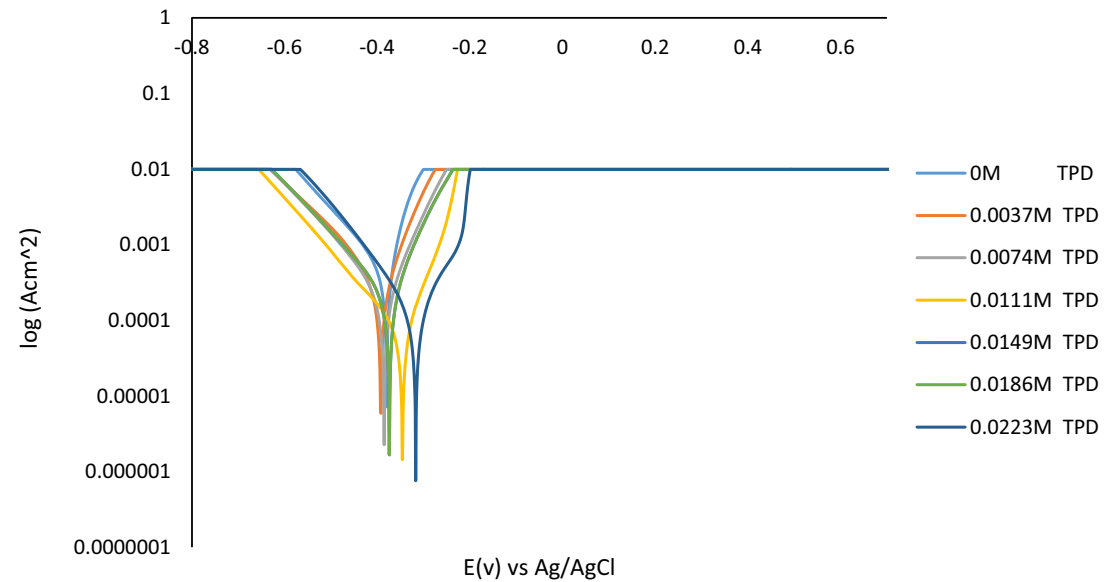

and higher concentrations of the organic compound due to lateral repulsion between the inhibitor molecules which results in weak inhibitor covering over the steel surface and hence significant increase in corrosion rate. Observation of data from unpublished research identifies similar phenomenon for $\mathrm{n}, \mathrm{n}$ diphenylthiourea in $\mathrm{HCl}$. The combined action/synergistic effect of the compounds in TPD displayed remarkable improvement in corrosion inhibition and inhibition efficiency [26, 27].

\section{Inhibition mechanism}

The classification of an organic compound as anodic- or cathodic-type inhibitor depends on the displacement of the corrosion potential values within and beyond $85 \mathrm{mV}$ in the anodic or cathodic direction [28, 29]. The maximum displacement value in $0.5 \mathrm{M} \mathrm{H}_{2} \mathrm{SO}_{4}$ is $73 \mathrm{mV}$ in the anodic direction and $17 \mathrm{mV}$ in the anodic direction for $1 \mathrm{M} \mathrm{HCl}$, and thus in $0.5 \mathrm{M} \mathrm{H}_{2} \mathrm{SO}_{4}$ and $1 \mathrm{M} \mathrm{HCl}$, TPD can be 
Fig. 7 Comparison plot of polarization scans for low carbon steel in $0.5 \mathrm{M} \mathrm{HCl}$ solution at $0 \mathrm{M}$ TPD

$-0.0223 \mathrm{M}$ TPD concentration

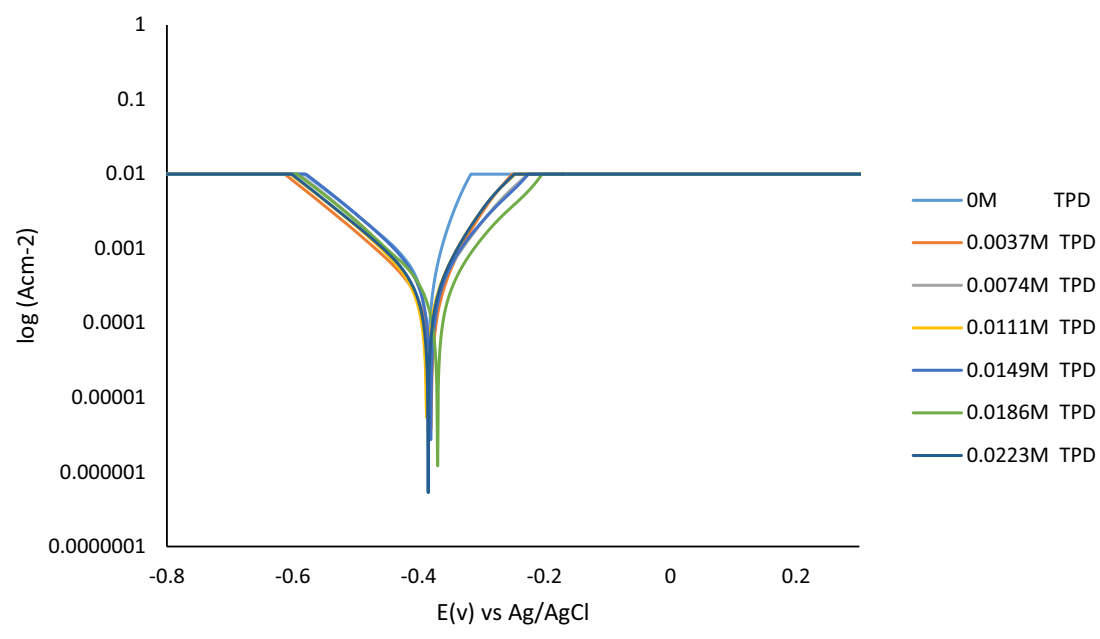

classified as mixed-type inhibitor with cathodic and anodic inhibiting characteristics. TPD has strong influence on the entire electrochemical process as the polarization resistance in Tables 3 and 4 increases with increase in inhibition efficiency till the maximum studied concentration. Organic compounds inhibit through surface coverage and adsorption which stifles the redox electrochemical process. The amines functional groups in TPD are nucleophiles that form a variety of electrophilic compounds due to the basic functionality of their nitrogen atoms and the electrophilic substitutions [30-32]. The unshared electron pair of the nitrogen atom forms a coordinate bond with a proton released from the ionized atoms at the steel surface. Amines from TPD react with acids to give salts and the valence steel electrons to produce chemical complexes responsible for the compact impenetrable barrier which strongly adsorbs to the steel and inhibits corrosion. The adsorption, however, may be considered to be due to physical and chemical reactions. The hydrophilic nature of protonated TPD functional groups and heteroatoms with their hydrophobic substituent (thiol) conforms the inhibitor molecules during adsorption process to form a polymolecular barrier layer that reliably screens the metal from the corrosive medium. The thiol molecules form a monomolecular layer by means of their strong affinity to metal and their self-assembly ability due to hydrophobic interaction.

\section{Adsorption isotherm}

The mechanism of corrosion process can be further analysed on the support of adsorption behaviour of the TPD inhibitor on the steel surface. Adsorption isotherms are very important in determining the nature of organometallic interactions [33, 34]. Adsorption of TPD at the metal/solution interface is due to the chemical bonding through chemisorption mechanism between the inhibitor and the valence atoms at the metal surface. Langmuir and Frumkin adsorption isotherms were applied to describe the adsorption mechanism in the acid solutions, as they provided the best fits.

The isotherms are of the general form:

$f(\theta, x) \exp (-2 a \theta)=K C$

where $f(\theta, x)$ is the configuration factor which depends upon the physical model and assumptions, the basis for the derivative of the isotherm, $\theta$ is the surface coverage, $C$ is the inhibitor concentration, $x$ is the size ration, " $a$ " is the molecular interaction parameter and $K$ is the equilibrium constant of adsorption process.

The general equation for Langmuir isotherm is,

$\left[\frac{\theta}{1-\theta}\right]=K_{\mathrm{ads}} C$

and rearranging

$K_{\mathrm{ads}} C=\left[\frac{\theta}{1+K_{\mathrm{ads}} \theta}\right]$

where $K_{\text {ads }}$ is the equilibrium constant of the adsorption process. The plots of TPD concentration/ $\theta$ versus the TPD concentration for carbon steel in $0.5 \mathrm{M} \mathrm{H}_{2} \mathrm{SO}_{4}$ and $1 \mathrm{M} \mathrm{HCl}$ are continuous (Figs. 8, 9) indicating the Langmuir adsorption. The divergence of the slope in Fig. 8 from unity is as a result of the electrochemical interaction among the adsorbed TTD cations on the metal surface and changes in the values of Gibbs free energy with increase in surface coverage. 
Fig. 8 Plots of TPD

concentration $/ \theta$ and TPD

concentration for $0.5 \mathrm{M} \mathrm{H}_{2} \mathrm{SO}_{4}$
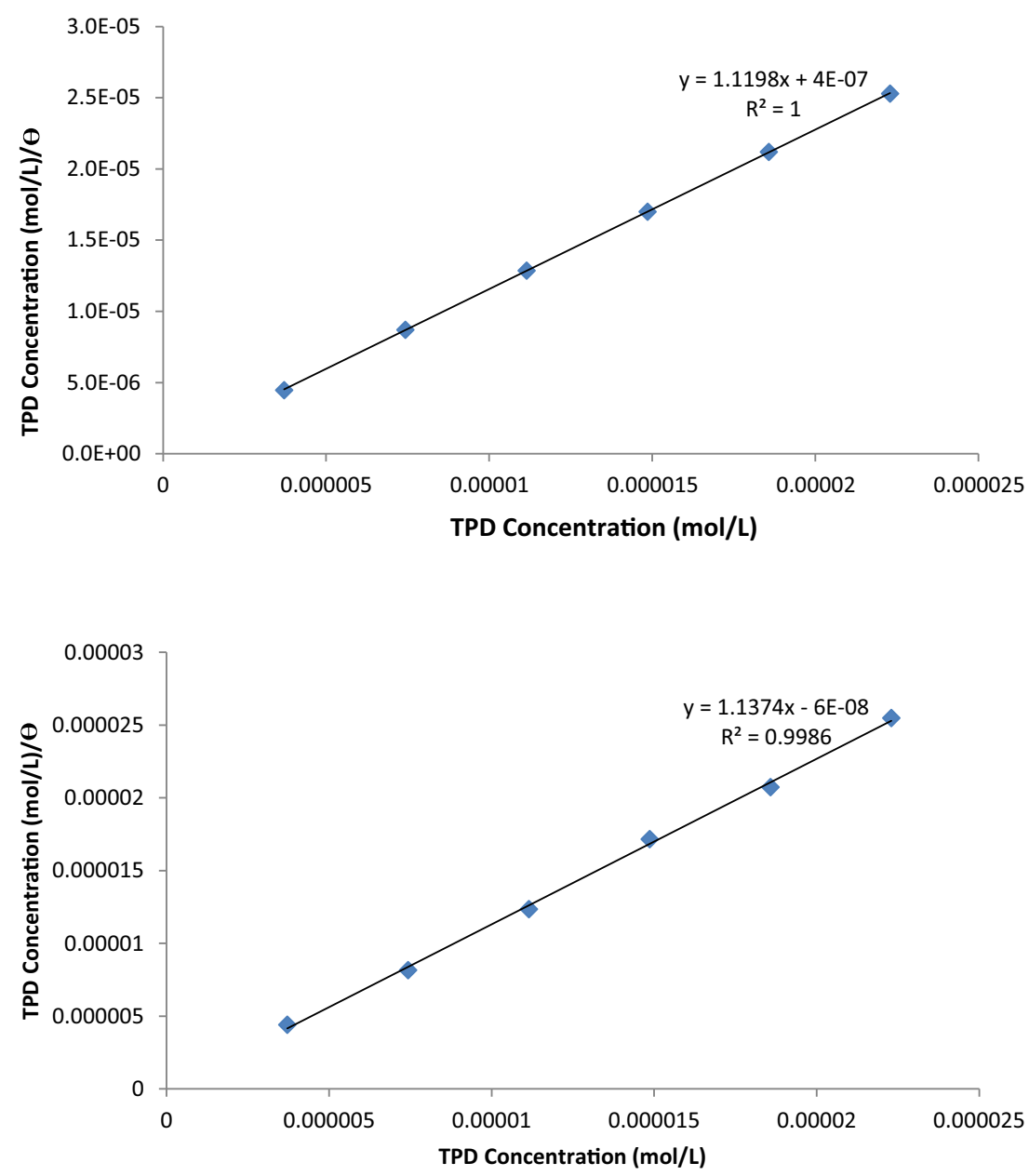

Fig. 9 Plots of TPD concentration $/ \theta$ and TPD concentration for $1 \mathrm{M} \mathrm{HCl}$
Langmuir isotherm states the following: the metal surface has a definite proportion of adsorption sites with one adsorbate and Gibbs free energy of adsorption has the same value for the sites, independent of the value of surface coverage [35].

Frumkin isotherm postulates unit coverage at high TPD concentrations and the alloy surface is not homogeneous, i.e. the effect of lateral interaction is significant. Only the active sites of the metal surface where adsorption occurs are considered. The mathematical expressions of Frumkin adsorption isotherm is

$$
\begin{aligned}
& \log [C \times(\theta / 1-\theta)]=2.303 \log K+2 \alpha \theta \\
& K C=(\theta / 1-\theta) \exp (\theta / 1-\theta)
\end{aligned}
$$

where $K$ is the equilibrium constant of adsorption and $\alpha$ is the lateral interaction term describing the interaction between the adsorbed TPD molecules. Graphical plots of $\theta / 1-\theta$ versus TPD concentration presented in Figs. 9 and 10 are continuous. The values of lateral interaction parameter are shown in Table 5. Increase in TPD concentration and surface coverage results in decrease in the lateral interaction term $(\alpha)$, suggesting that the inhibitor stifles the electrochemical process responsible for corrosion through adsorption on active sites on the steel surface. The " $\alpha$ " values show that the attraction between TTD molecules is weak.

\section{Thermodynamics of the corrosion inhibition mechanism}

Gibbs free energy $\left(\Delta G_{\text {ads }}\right.$ ) (Table 6) for the TPD corrosion inhibition was evaluated from the equilibrium constant of adsorption according to the equation.

$\Delta G_{\text {ads }}=-2.303 R T \log \left[55.5 K_{\mathrm{ads}}\right]$

where 55.5 is the molar concentration of water in the solution, $R$ is the universal gas constant, $T$ is the absolute temperature and $K_{\text {ads }}$ is the equilibrium constant of 
Fig. 10 Plots of $(\theta / 1-\theta)$ and TPD concentration in $1 \mathrm{M} \mathrm{HCl}$

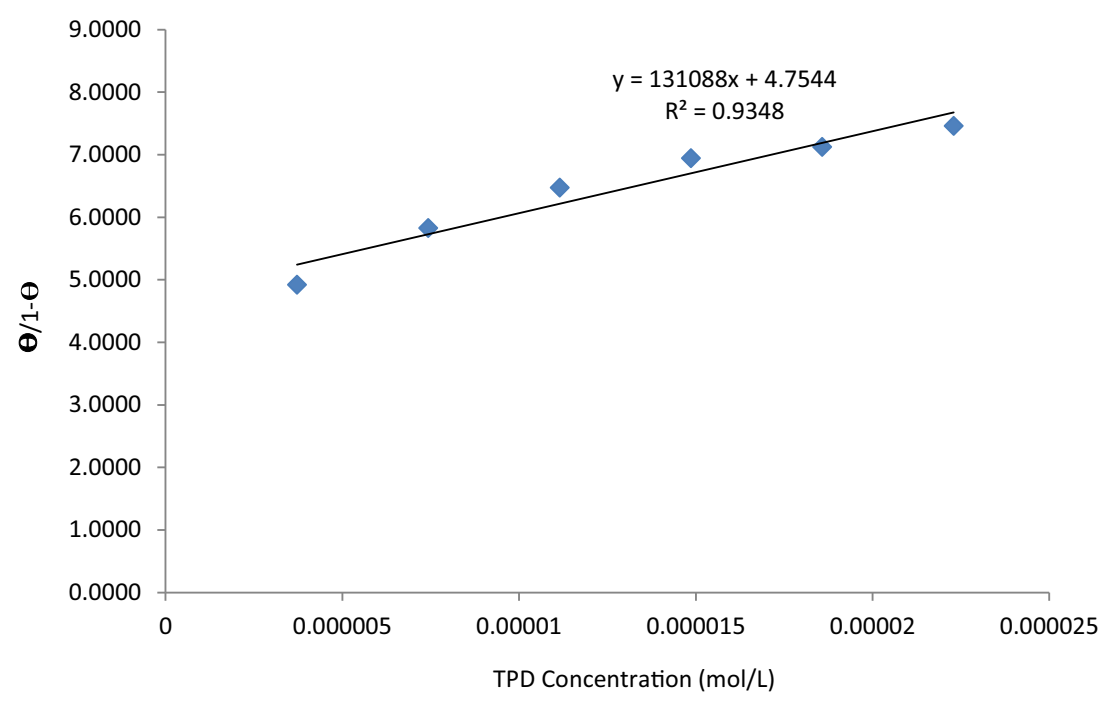

Table 5 Relationship between lateral interaction parameter, surface coverage and TPD concentration from Frumkin adsorption isotherm

\begin{tabular}{llll}
\hline $\begin{array}{l}\text { Lateral } \\
\text { interaction } \\
(\alpha)\end{array}$ & $\begin{array}{l}\text { Equilibrium constant } \\
\text { of adsorption }(K)\end{array}$ & $\begin{array}{l}\text { Surface } \\
\text { coverage } \\
(\theta)\end{array}$ & $\begin{array}{l}\text { TPD } \\
\text { concentration } \\
(\mathrm{mol} / \mathrm{L})\end{array}$ \\
\hline-10.14 & 181969.17 & 0.8312 & 0.003715 \\
-9.88 & 266194.77 & 0.8535 & 0.007431 \\
-9.80 & 376806.42 & 0.8662 & 0.011146 \\
-9.77 & 485401.77 & 0.8741 & 0.014861 \\
-9.67 & 476025.26 & 0.8769 & 0.018576 \\
-9.67 & 581038.31 & 0.8818 & 0.022292 \\
\hline
\end{tabular}

Table 6 Data of Gibbs free energy, TPD concentration and inhibition efficiency for $0.5 \mathrm{M} \mathrm{H}_{2} \mathrm{SO}_{4}$

\begin{tabular}{lll}
\hline $\begin{array}{l}\text { TPD concentration } \\
(\mathrm{mol} / \mathrm{L})\end{array}$ & $\begin{array}{l}\text { Inhibition efficiency } \\
(\%)\end{array}$ & $\begin{array}{l}\text { Gibbs free energy } \\
\left(\Delta G_{\text {ads }}\right)\end{array}$ \\
\hline 0.0037 & 83.12 & -44.88 \\
0.0074 & 85.35 & -43.59 \\
0.0111 & 86.62 & -42.84 \\
0.0149 & 87.41 & -42.30 \\
0.0186 & 87.69 & -41.81 \\
0.0223 & 88.18 & -41.48 \\
\hline
\end{tabular}

adsorption. $K_{\text {ads }}$ is related to surface coverage $(\theta)$ by the following Eq. (8).

The $\Delta G_{\text {ads }}$ data values in Tables 6 and 7 vary with change in inhibitor concentration, and this supports the Langmuir model due to the nonhomogeneous nature of the metal surface such as microscopic voids, non-metallic inclusion, and impurities. Conventionally, values of $\Delta G_{\text {ads }}$ of around $-20 \mathrm{~kJ} / \mathrm{mol}$ or below depict physisorption
Table 7 Data of Gibbs free energy, TPD concentration and inhibition efficiency for $0.5 \mathrm{M} \mathrm{HCl}$

\begin{tabular}{lll}
\hline $\begin{array}{l}\text { TPD concentration } \\
(\mathrm{mol} / \mathrm{L})\end{array}$ & $\begin{array}{l}\text { Inhibition efficiency } \\
(\%)\end{array}$ & $\begin{array}{l}\text { Gibbs free energy } \\
\left(\Delta G_{\mathrm{ads}}\right)\end{array}$ \\
\hline 0.0037 & 83.97 & -35.09 \\
0.0074 & 90.92 & -34.98 \\
0.0111 & 90.23 & -33.77 \\
0.0149 & 86.50 & -32.15 \\
0.0186 & 89.59 & -32.33 \\
0.0223 & 87.42 & -31.35 \\
\hline
\end{tabular}

reactions and values of about $-40 \mathrm{~kJ} / \mathrm{mol}$ or above involve chemical reactions associated with chemisorption mechanism which tends to be more sustainable in corrosion inhibition than physisorption. The value of $\Delta G_{\text {ads }}$ for the carbon steel in $0.5 \mathrm{M} \mathrm{H}_{2} \mathrm{SO}_{4}$ (Table 6) shows chemisorption of TPD on the steel surface; in $1 \mathrm{M} \mathrm{HCl}$ (Table 7), the $\Delta G_{\text {ads }}$ values show physiochemical (physisorption as well as chemisorption) adsorption mechanism. The negative values of $\Delta$ Gads show that TTD adsorption on the metal surface is spontaneous [35-38].

\section{X-Ray diffraction analysis}

X-ray diffraction (XRD) patterns of the carbon steel surface which gives qualitative information about the possible phases present before and after the corrosion test in $0.5 \mathrm{M}$ $\mathrm{H}_{2} \mathrm{SO}_{4}$ and $1 \mathrm{M} \mathrm{HCl}$ solutions with TPD inhibitor are shown in Fig. 11. The peak values at $2 \theta$ values showed the presence of iron and carbon only on the steel surface. Observation of the diffraction peaks for the inhibited showed the absence of iron oxides and chemical 

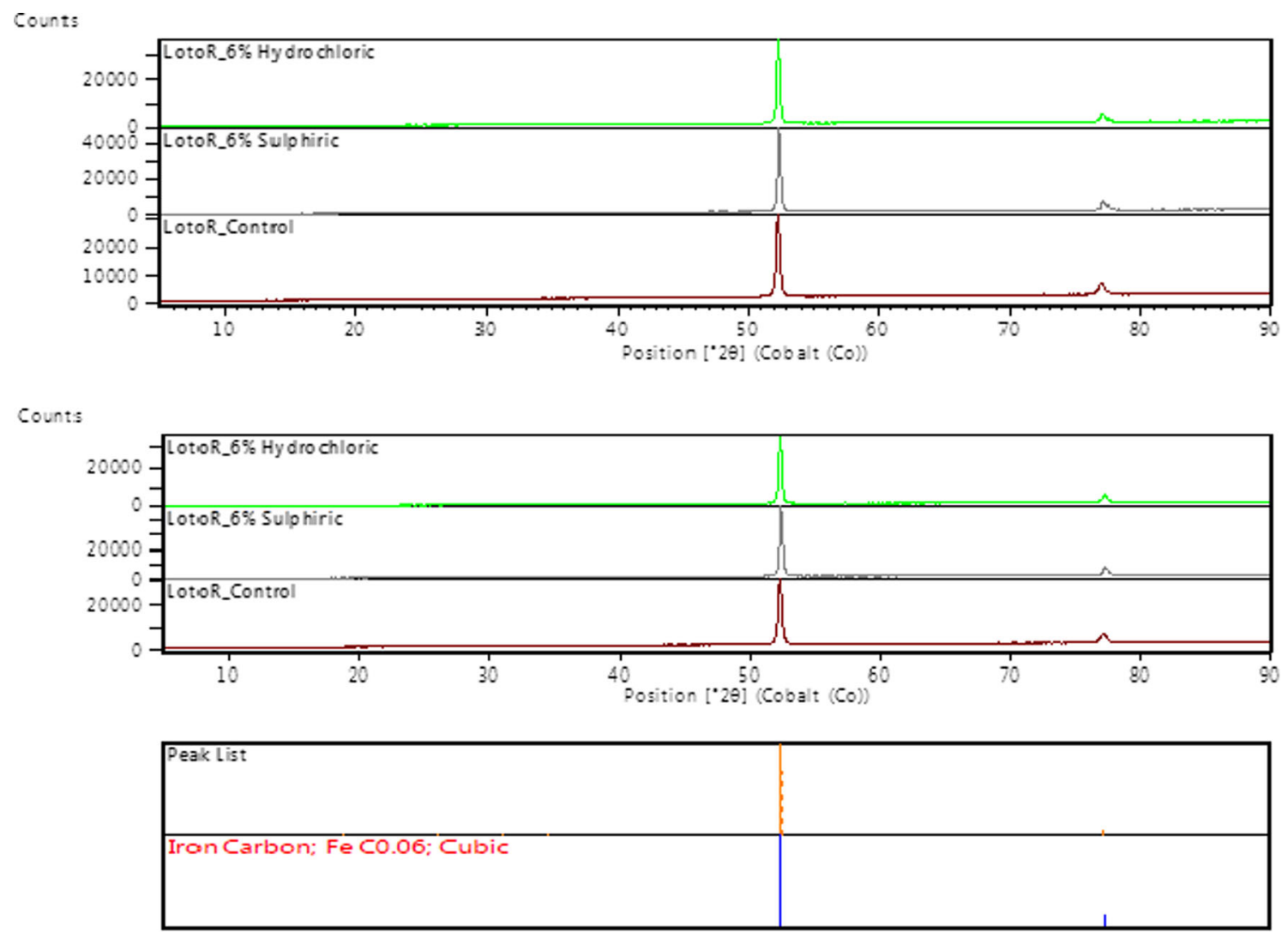

Fig. $11 \mathrm{XRD}$ pattern of low carbon steel after immersion in $0.5 \mathrm{M} \mathrm{H}_{2} \mathrm{SO}_{4}$ and in $1 \mathrm{M} \mathrm{HCl}$ with TPD addition

compounds associated with corrosion, further proving the inhibition to be due to the electrochemical action of the functional groups of TPD and selective adsorption onto the steel

\section{Optical microscopy analysis}

The optical microscopy images of the carbon steel surfaces before and after immersion in the acid media, without the addition of TTD, are given in Fig. 12a-c. Figure 12a shows the steel sample before immersion, and the serrated surface is due to machining during sample preparation. Figure 12b, c shows the steel surfaces after $240 \mathrm{~h}$ of immersion in $0.5 \mathrm{M} \mathrm{H}_{2} \mathrm{SO}_{4}$ and $1 \mathrm{M} \mathrm{HCl}$ without TTD addition. In Fig. 12b, c, the images reveal a rough surface due to corrosion and anodic oxidation resulting from the action of $\mathrm{SO}_{4}{ }^{2-}$ and $\mathrm{Cl}^{-}$ions in the acid solution. The chloride ions accelerate the hydrolysis and diffusion of ionized atoms of $\mathrm{Fe}$, causing rapid corrosion and deterioration of the steel sample.

The surface topography of the carbon steel (Fig. 12d, e) is as a result of the presence of TPD in the acid solution compared with the control and uninhibited sample. The effectiveness of the protective film is clearly visible on the images. Precipitates form on the steel surface, coating the steel from corrosion and producing the micrographs below. The selective precipitation of TPD on the surface is clearly visible on the images after the electrochemical tests due to the strong adsorption of its molecules through electrolytic diffusion and electrostatic attraction onto the surface of the steel, displacing the corrosive anions through the formation of a stronger bond with the charged surface atoms of the steel. The protective film of TPD formed on the specimen surface exhibited good inhibition performance for the corrosion of carbon steel in the acid solutions and the observation is in good agreement with the weight loss and electrochemical experiments.

\section{Conclusions}

The corrosion inhibition performance of the synergistic effect of $p$-phenylenediamine and $n, n$ diphenylthiourea (TPD) on mild steel in the acid solutions showed excellent results. The corrosion rate reduced sharply with TPD 

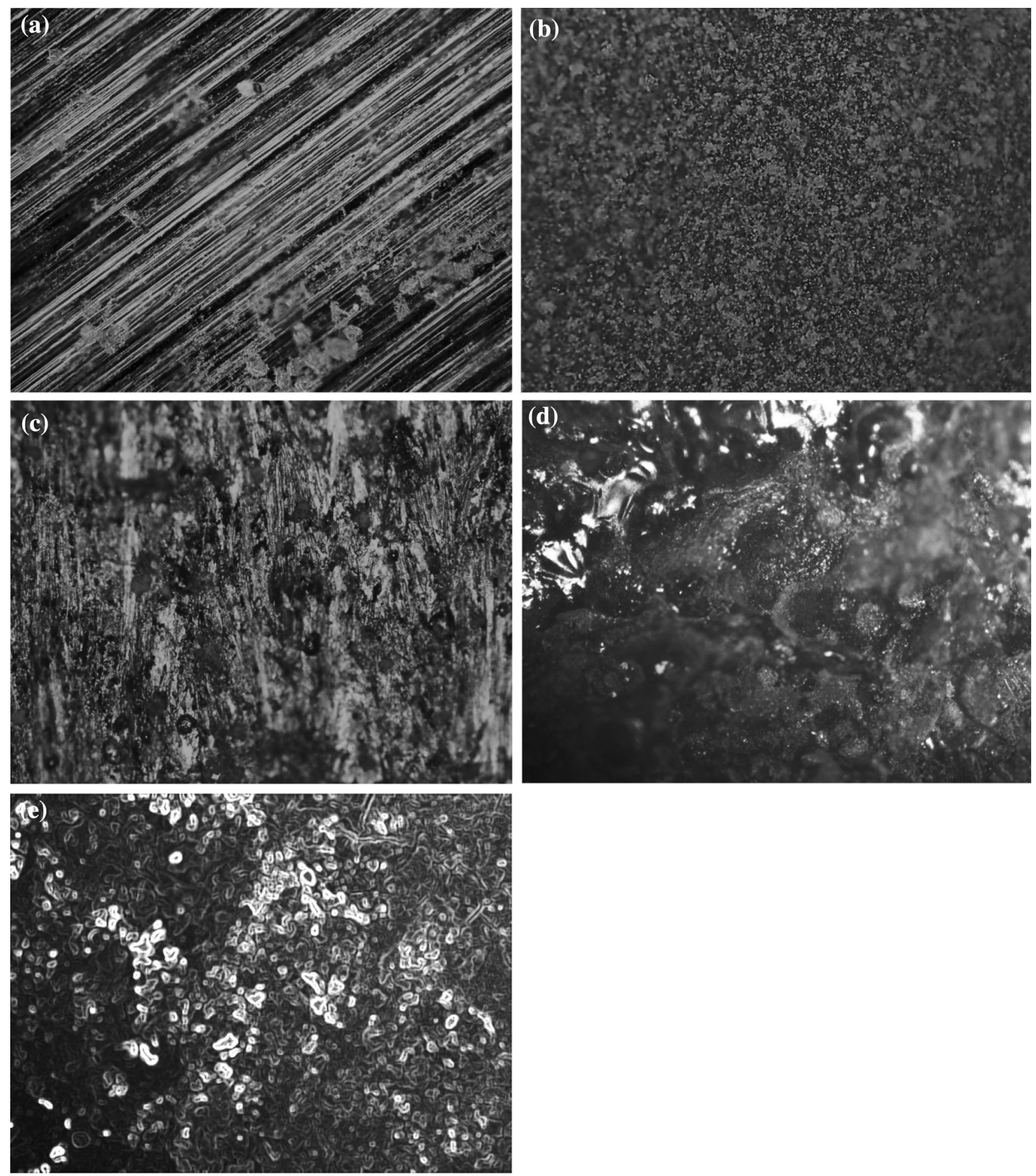

Fig. 12 Optical microscopy images at $\mathrm{x} 50$ of low carbon steel: a before immersion, b after immersion in $0.5 \mathrm{M} \mathrm{H}_{2} \mathrm{SO}_{4}$, c after immersion in $0.5 \mathrm{M} \mathrm{HCl}, \mathbf{d}$ after immersion in $0.5 \mathrm{M} \mathrm{H}_{2} \mathrm{SO}_{4}+$ TTD inhibitor, e after immersion in $0.5 \mathrm{M} \mathrm{HCl}+$ TTD inhibitor

addition from lowest to highest concentration, significantly influencing the interfacial redox electrochemical process responsible for corrosion through adsorption on the steel surface. Mixed inhibition behaviour was observed from the corrosion potential values of the potentiodynamic analysis. Optical microscopy characterization shows the change on the surface topography and morphology of the steel surface between the inhibited and uninhibited steel samples. 
Acknowledgments The authors acknowledge the Department of Mechanical Engineering, College of Engineering, Covenant University, Ota, Ogun State, Nigeria and the Department of Chemical, Metallurgical and Materials Engineering, Tshwane University of Technology, Pretoria, South Africa, for the provision of research facilities for this work.

Open Access This article is distributed under the terms of the Creative Commons Attribution 4.0 International License (http://crea tivecommons.org/licenses/by/4.0/), which permits unrestricted use, distribution, and reproduction in any medium, provided you give appropriate credit to the original author(s) and the source, provide a link to the Creative Commons license, and indicate if changes were made.

\section{References}

1. Fouda AS, Hamdy BA (2013) Aqueous extract of propolis as corrosion inhibitor for carbon steel in aqueous solutions. Afr $\mathbf{J}$ Pure Appl Chem 7(10):350-359

2. Burubai W, Dagogo G (2007) Comparative study of inhibitors on the corrosion of mild steel reinforcement in concrete. Agric Eng Int CIGR E-J 9:1-10

3. Liu GQ, Zhu ZY, Ke W, Han CI, Zeng CL (2001) Corrosion. Natl Assoc Chem Eng 57(8):730

4. Ilevbare GO, Burstein GT (2003) The inhibition of pitting corrosion of stainless steel by chromate and molybdate ions. Corros Sci 45:1545-1569

5. Munoz AI, Anton JG, Nuevalos SL, Guinon JL, Herranz VP (2004) Corrosion studies of Austenitic and duplex stainless steels in aqueous lithium bromide solution at different temperatures. Corros Sci 46:2955-2974

6. Cui ZD, Wu SL, Zhu SL, Yang XJ (2006) Study on corrosion properties of pipelines in simulated produced water saturated with supercritical $\mathrm{CO}_{2}$. Appl Surf Sci 252:2368-2374

7. Leelavathi S, Rajalakshmi R (2013) Dodonaea viscosa (L.) leaves extract as acid corrosion inhibitor for mild steel-a green approach. J Mater Environ Sci 4(5):625-638

8. Trabanelli G (1991) Inhibitors-an old remedy for a new challenge. Corrosion 47(6):410-419

9. Satapathy AK, Gunasekaran G, Sahoo SC, Amit K, Rodrigues RV (2009) Corrosion inhibition by Justicia gendarussa plant extract in hydrochloric acid solution. Corros Sci 51(12):2848-2856

10. Ghazoui A, Bencaht N, Al-Deyab SS, Zarrouk A, Hammouti B, Ramdani M, Guenbour M (2013) An Investigation of two novel pyridazine derivatives as corrosion inhibitor for C38 steel in 1.0 M HCl. Int J Electrochem Sci 8:2272-2292

11. Al Hamzi AH, Zarrok H, Zarrouk A, Salghi R, Hammouti B, AlDeyab SS, Bouachrine M, Amine A, Guenoun F (2013) The role of acridin-9(10H)-one in the inhibition of carbon steel corrosion: thermodynamic, electrochemical and DFT studies. Int J Electrochem Sci 2013(8):2586-2605

12. Zarrok H, Zarrouk A, Salghi R, Oudda H, Hammouti B, Assouag M, Taleb M, Ebn Touhami M, Bouachrine M, Boukhris S (2012) Gravimetric and quantum chemical studies of 1-[4-acetyl-2-(4chlorophenyl)quinoxalin-1(4H)-yl]acetone as corrosion inhibitor for carbon steel in hydrochloric acid solution. J Chem Pharm Res 4(12):5056-5066

13. Zarrok H, Zarrouk A, Salghi R, Ramli Y, Hammouti B, Assouag M, Essassi EM, Oudda H, Taleb M (2012) 3,7Dimethylquinoxalin-2-(1H)-one for inhibition of acid corrosion of carbon steel J Chem. Pharm Res 4(12):5048-5055
14. Zarrouk A, Zarrok H, Salghi R, Hammouti B, Bentiss F, Touir R, Bouachrine M (2013) Evaluation of N-containing organic compound as corrosion inhibitor for carbon steel in phosphoric acid. J Mater Environ Sci 4(2):177-192

15. Zarrouk A, Zarrok AH, Salghi R, Bouroumane N, Hammouti B, Al-Deyab SS, Touzani R (2012) The Adsorption and Corrosion Inhibition of 2-[bis-(3,5-dimethyl-pyrazol-1-ylmethyl)-amino]pentanedioic acid on carbon steel corrosion in $1.0 \mathrm{~m} \mathrm{HCl}$. Int $\mathrm{J}$ Electrochem Sci 7:10215-10232

16. Ben Hmamou D, Salghi R, Zarrouk A, Zarrok H, Al-Deyab SS, Benali O, Hammouti B (2012) The inhibited effect of phenolphthalein towards the corrosion of $\mathrm{C} 38$ steel in hydrochloric acid. Int J Electrochem Sci 7:8988-9003

17. Zarrouk A, Messali M, Aouad MR, Assouag M, Zarrok H, Salghi R, Hammouti B, Chetouani A (2012) Some new ionic liquids derivatives: synthesis, characterization and comparative study towards corrosion of C-steel in acidic media. J Chem Pharm Res 4(7):3427-3436

18. Torres VV, Amado RS, Faia de Sa C, Fernandez TL, Riehl CAS, Torres AG, D'Elia E (2011) Inhibitory action of aqueous coffee ground extracts on the corrosion of carbon steel in $\mathrm{HCl}$ solution. Corros Sci 53:2385-2392

19. Edrah S, Hasan SK (2010) Studies on thiourea derivatives as corrosion inhibitor for aluminum in sodium hydroxide solution. J Appl Sci Res 6(8):1045-1049

20. Fekry AM, Mohamed RR (2010) Acetyl thiourea chitosan as an eco-friendly inhibitor for mild steel in sulphuric acid medium. Electrochim Acta 55(6):1933-1939

21. Awad K (2004) Semiempirical investigation of the inhibition efficiency of thiourea derivatives as corrosion inhibitors. J Electro Chem 567(2):219-225

22. Chao CY, Lin LF, Macdonald DD (1981) A point defect model for anodic passive films. I. Film growth kinetics. J Electrochem Soc 128:1187-1194

23. Loto RT, Loto CA (2012) Effect of $P$-phenylenediamine on the corrosion of austenitic stainless steel type 304 in hydrochloric acid. Int J Electrochem Sci 7:9423-9440

24. Heckerman N, Snavely E Jr, Payne JS Jr (1966) Effects of anions on corrosion inhibition by organic compounds. J Electrochem Soc 113:677-681

25. Felicia RS, Santhanalakshmi S, Wilson SJ, John AA, Susai R (2004) Synergistic effect of succinic acid and $\mathrm{Zn} 2+$ in controlling corrosion of carbon steel. Bull Electrochem 20(12):561-565

26. Loto RT, Loto CA, Popoola API, Fedotova T (2015) Electrochemical effect of 1, 4-diaminobenzene on the corrosion inhibition of mild steel in dilute acid media. Der Pharma Chemica 7(5):72-93

27. Susai RS, Mary R, Noreen A, Ramaraj R (2002) Synergistic corrosion inhibition by the sodium dodecylsulphate-Zn $2+$ system. Corros Sci 44(10):2243-2252

28. Sahin M, Bilgiç S, Yılmaz H (2002) The inhibition effects of some cyclic nitrogen compounds on the corrosion of the steel in $\mathrm{NaCl}$ mediums. Appl Surf Sci 195(104):1-7

29. Ruppel DT, Dexter SC, Luther GW (2001) III role of manganese dioxide in corrosion in the presence of natural biofilms. Corrosion J 57(1):863-873

30. Gad Alla AG, Tamous HM (1990) Structural investigation of pyrazole derivatives as corrosion inhibitors for delta steel in acid chloride solutions. J Appl Electrochem 20(3):488-493

31. Quraishi MA, Sharma HK (2002) 4-Amino-3-butyl-5-mercapto1, 2, 4-triazole: a new corrosion inhibitor for mild steel in sulphuric acid. Mater Chem Phys 78(1):18-21

32. Quraishi MA, Ansari FA, Jamal D (2004) Corrosion inhibition of Tin by some amino acids in citric acid solution. Indian $\mathrm{J}$ Chem Technol 11:271-274 
33. Hirozawa ST (1995) Proceedings of 8th European symposium on corrosion inhibition. Ann University, Ferrara, vol 1, p 25

34. Villamil RFV, Corio P, Rubin JC, Agostinho SMI (1999) Effect of sodium dodecylsulfate on copper corrosion in sulfuric acid media in the absence and presence of benzotriazole. J Electroanal Chem 472:112-119

35. Eddy NO, Mamza PAP (2009) Inhibitive and adsorption properties of ethanol extract of seeds and leaves of Azardirachta indica on the corrosion of mild steel in $\mathrm{H}_{2} \mathrm{SO}_{4}$. Port Electrochim Acta 27(4):443-456

36. Hosseini MG, Mertens SFL, Arshadi MR (2003) Synergism and antagonism in mild steel corrosion inhibition by sodium dodecylbenzenesulphonate and hexamethylenetetramine. Corros Sci 45:1473-1489

37. Solmaz R (2010) Investigation of the inhibition effect of 5-((E)-4phenylbuta-1,3-dienylideneamino)-1,3,4-thiadiazole-2-thiol Schiff base on mild steel corrosion in hydrochloric acid. Corros Sci 52(10):3321-3330

38. Döner A, Solmaz R, Özcan M, Kardaş G (2011) Experimental and theoretical studies of thiazoles as corrosion inhibitors for mild steel in sulphuric acid solution. Corros Sci 53(9):2902-2913 